OPEN ACCESS

Edited by:

Christophe Matthys, KU Leuven, Belgium

Reviewed by:

Roger Bouillon, KU Leuven, Belgium Zhongheng Zhang,

Sir Run Run Shaw Hospital, China

*Correspondence: Mohammad Rizki Akbar m.r.akbar@unpad.ac.id

Specialty section: This article was submitted to Nutritional Immunology, a section of the journal

Frontiers in Nutrition

Received: 29 January 2021 Accepted: 05 March 2021 Published: 29 March 2021

Citation:

Akbar MR, Wibowo A, Pranata $R$ and Setiabudiawan B (2021) Low Serum 25-hydroxyvitamin D (Nitamin D) Level Is Associated With Susceptibility to COVID-19, Severity, and Mortality: A Systematic Review and Meta-Analysis. Front. Nutr. 8:660420. doi: 10.3389/fnut.2021.660420

\section{Low Serum 25-hydroxyvitamin D (Vitamin D) Level Is Associated With Susceptibility to COVID-19, Severity, and Mortality: A Systematic Review and Meta-Analysis}

\author{
Mohammad Rizki Akbar $^{1 *}$, Arief Wibowo ${ }^{1}$, Raymond Pranata ${ }^{1,2}$ and Budi Setiabudiawan ${ }^{3}$ \\ 'Department of Cardiology and Vascular Medicine, Faculty of Medicine, Universitas Padjadjaran/Dr. Hasan Sadikin General \\ Hospital, Bandung, Indonesia, ${ }^{2}$ Faculty of Medicine, Universitas Pelita Harapan, Tangerang, Indonesia, ${ }^{3}$ Department of Child \\ Health, Faculty of Medicine, Universitas Padjadjaran/Dr. Hasan Sadikin General Hospital, Bandung, Indonesia
}

Background: This systematic review and meta-analysis aimed to assess whether low serum 25-hydroxyvitamin D (25-OHD) level is associated with susceptibility to COVID-19, severity, and mortality related to COVID-19.

Methods: Systematic literature searches of PubMed, Scopus, and Embase database up until 9 December 2020. We include published observational prospective and retrospective studies with information on 25-OHD that reported main/secondary outcome. Low serum 25-OHD refers to participants with serum 25-OHD level below a cut-off point ranging from 20 to $30 \mathrm{ng} / \mathrm{mL}$. Other cut-off values were excluded to reduce heterogeneity. The main outcome was mortality defined as non-survivor/death The secondary outcome was susceptibility and severe COVID-19.

Results: There were 14 studies comprising of 999,179 participants. Low serum 25OHD was associated with higher rate of COVID-19 infection compared to the control group (OR $=2.71$ [1.72, 4.29], $\left.p<0.001 ; r^{2}: 92.6 \%\right)$. Higher rate of severe COVID-19 was observed in patients with low serum 25-OHD (OR = 1.90 [1.24, 2.93], $p=0.003$; $l^{2}$ : $55.3 \%$ ), with a sensitivity of $83 \%$, specificity of $39 \%$, PLR of 1.4 , NLR of 0.43 , and DOR of 3. Low serum 25-OHD was associated with higher mortality $(\mathrm{OR}=3.08[1.35,7.00]$, $\left.p=0.011 ; l^{2}: 80.3 \%\right)$, with a sensitivity of $85 \%$, specificity of $35 \%$, PLR of 1.3 , NLR of 0.44 , and DOR of 3 . Meta-regression analysis showed that the association between low serum $25-\mathrm{OHD}$ and mortality was affected by male gender $(\mathrm{OR}=1.22[1.08,1.39], p=$ 0.002), diabetes $(\mathrm{OR}=0.88$ [0.79, 0.98], $p=0.019)$.

Conclusion: Low serum 25-OHD level was associated with COVID-19 infection, severe presentation, and mortality.

Keywords: coronavirus, COVID-19, immunity, infection, mortality, severity, susceptibility, vitamin D 


\section{INTRODUCTION}

Coronavirus disease 2019 (COVID-19) is one of the most prevalent diseases to date (1). Although most COVID-19 patients have mild-moderate symptom, a considerable number of patients, especially in patients with pre-existing comorbidities, experiences severe infection that might lead to death $(2,3)$.

Vitamin D is known to modulate immune response (4) and its deficiency was associated with respiratory distress in patients hospitalized for pneumonia (5). Nevertheless, controversies exist, a study indicates that low serum 25-hydroxyvitamin D (25-OHD) was not associated with lung injury or mortality in severe sepsis and trauma (6). Numerous studies on vitamin D in COVID-19 patients also have conflicting results, similar to other diseases. This systematic review and meta-analysis aimed to assess whether low serum 25-OHD is associated with susceptibility to COVID19 , severity, and mortality related to COVID-19.

\section{MATERIALS AND METHODS}

This study follows the Preferred Reporting Items for Systematic Reviews and Meta-Analyses (PRISMA) reporting guideline.

\section{Eligibility Criteria}

The inclusion criteria were: (1) published observational retrospective and prospective studies, (2) Information on serum 25-OHD with a clear cut-off value ranging from 20 to $30 \mathrm{ng} / \mathrm{mL}$, (3) comparing patients with COVID-19 vs nonCOVID-19 OR severity in COVID-19 patients OR mortality in COVID-19 patients.

The paper was excluded if it fulfils one of the following: (1) reviews, (2) preprints, (3) non-research letters, (4) case reports, (5) commentaries, and (6) language other than English. We excluded preprints because of inconsistent credibility (7).

\section{Search Strategy and Study Selection}

We performed systematic literature search using PubMed, Scopus, and Embase databases were performed with keywords "COVID-19" OR "SARS-CoV-2" OR “2019-nCoV” AND

"Vitamin D" on 9 December 2020.

Duplicate records were removed and the title/abstract was screened by two independent authors. The full-texts of potentially eligible studies were assessed based on the inclusion and exclusion criteria.

\section{Data Extraction}

Two authors independently performed data extraction of first author, publication year, design, age, male (gender), hypertension, diabetes, serum 25-OHD status, the outcome of interest and its effect estimates.

Low serum 25-OHD refers to participants with serum 25OHD below a cut-off point ranging from 20 to $30 \mathrm{ng} / \mathrm{mL}$. Other cut-off values were excluded to reduce heterogeneity.

The main outcome was mortality defined as nonsurvivor/death. The secondary outcome was susceptibility and severe COVID-19. Susceptibility was calculated by comparing the COVID-19 positive cohort with the COVID-19 negative cohort. Severe COVID-19 was defined according to the criteria for severe CAP, including the need for intensive unit care or mechanical ventilation (8). The effect estimates of the main and secondary outcome were reported as odds ratios (ORs). Several parameters, including the sensitivity and specificity of low serum 25-OHD, the positive likelihood ratio (PLR) and negative likelihood ratio (NLR), and diagnostic odds ratio (DOR) of studies; and generate hierarchical summary receiver operating characteristic (HSROC) for mortality and severity.

Risk of bias assessment was performed by two independent authors using the Newcastle-Ottawa Scale (NOS). Arising discrepancies were resolved by discussion.

\section{Statistical Analysis}

DerSimonian and Laird random-effects model were used to generate pooled ORs and its $95 \%$ CI. $P \leq 0.05$ was considered as statistically significant. Assessment of heterogeneity was performed by using $I$-squared $\left(I^{2}\right)$ and Cochrane $Q$ test, in which an $I^{2}>50 \%$ or $p<0.10$ indicates significant heterogeneity. We performed the qualitative funnel plot analysis and the quantitative Egger's test in order to assess the possibility for publication bias and small-study effects. Sensitivity and specificity, PLR and NLR, and DOR were pooled; HSROC was generated. Restricted-maximum likelihood (REML) random-effects meta-regression was performed using age, male (gender), diabetes, and hypertension as covariates. To perform these analyses, STATA 16 (StataCorp LLC, Texas, US) was used.

\section{RESULTS}

There were 14 studies comprising of 999,179 participants in the qualitative and quantitative synthesis (9-22) (Figure 1). The baseline characteristics and risk of bias assessment based on NOS is displayed in Table 1. Severity occurs in 42\% (22-62\%). Mortality occurs in $24 \%(6-41 \%)$ of patients in the pooled analysis.

Meta-analysis showed that low serum 25-OHD was associated with higher rate of COVID-19 infection compared to the control group (OR $\left.=2.71[1.72,4.29], p<0.001 ; I^{2}: 92.6 \%, p<0.001\right)$ (Figure 2).

Higher rate of severe COVID-19 was observed in patients with low serum 25-OHD (OR $=2.19$ [1.17, 4.10], $p=$ $0.013 ; I^{2}: 64.3 \%, p=0.025$ ) (Figure 3A), with a sensitivity of 0.86 [0.79, 0.91], specificity of 0.39 [0.23, 0.57], PLR of $1.4[1.0,2.0]$, NLR of $0.36[0.16,0.83]$, and DOR of 4 $[1,12]$ (Figure 3B). Fagan's nomogram indicate that a low serum $25-\mathrm{OHD}$ was associated with $50 \%$ post-test probability and normal serum 25-OHD was associated with $21 \%$ posttest probability for mortality, in a sample with $42 \%$ pre-test probability (Figure 3C).

Low serum 25-OHD was associated with higher mortality $\left(\mathrm{OR}=3.08 \quad[1.35,7.00], p=0.011 ; I^{2}: 80.3 \%, p<\right.$ 0.001 ) (Figure 4A), with a sensitivity of 0.85 [0.68, 0.93], specificity of $0.35[0.26,0.45]$, PLR of $1.3[1.0,1.6]$, NLR of 0.44 [0.18, 1.08], and DOR of 3 [1, 9] (Figure 4B). Fagan's nomogram indicate that a low serum 25-OHD 


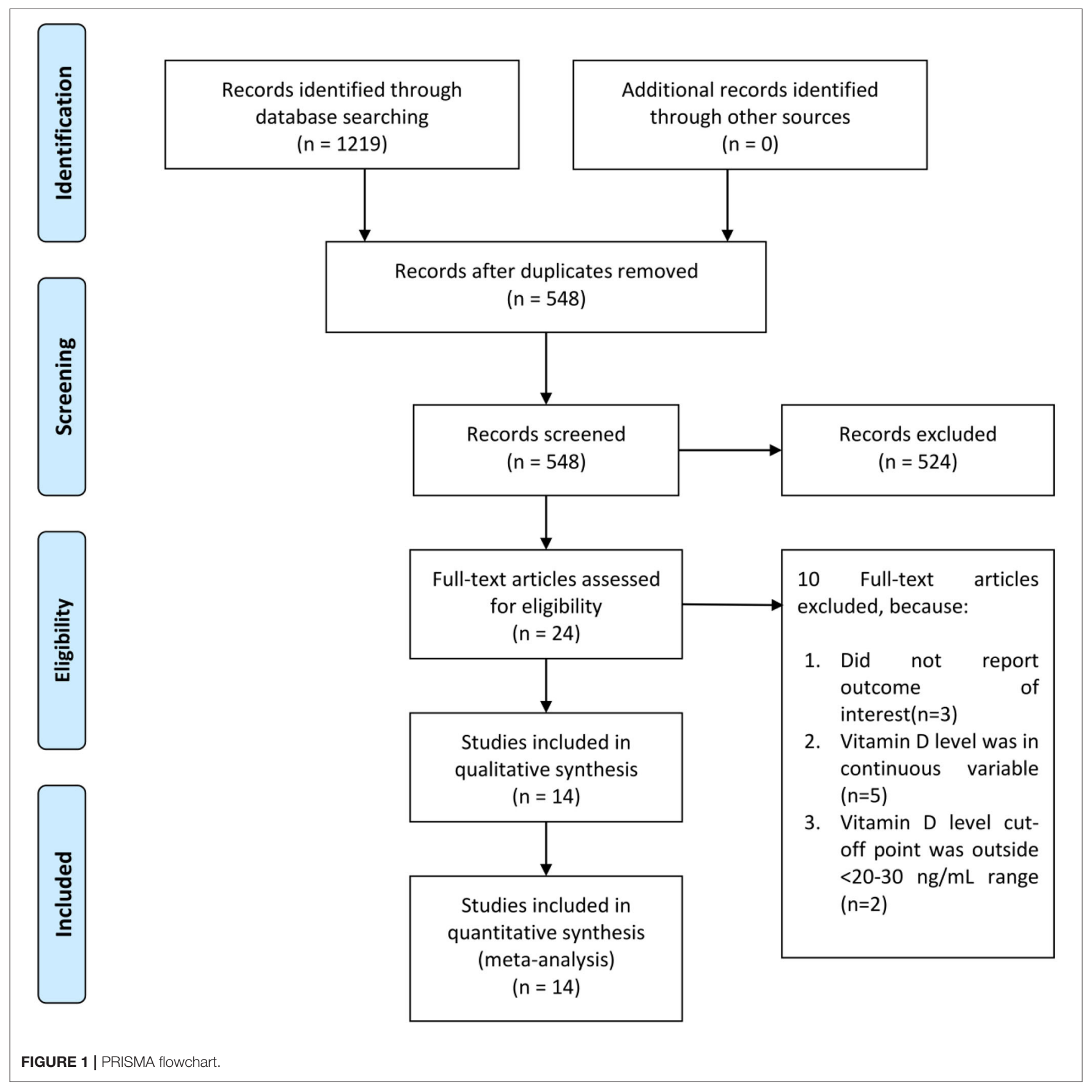

was associated with $29 \%$ post-test probability and normal serum $25-\mathrm{OHD}$ was associated with $12 \%$ post-test probability for mortality, in a sample with $24 \%$ pre-test probability (Figure 4C).

Funnel plot was asymmetrical for mortality, severity, and susceptibility. Egger's test indicates significant small-study effects for severity $(p=0.047)$ and mortality $(p=0.046)$. There was no indication of small-study effects for susceptibility $(p=0.615)$.

Meta-regression analysis showed that the association between low serum 25-OHD and COVID-19 infection was affected by age $(\mathrm{OR}=1.06[1.01,1.12], p=$ $0.020)$ and male gender $(\mathrm{OR}=1.04$ [1.00, 1.72$]$, $p=0.039)$.

Meta-regression analysis showed that the association between low serum 25-OHD and mortality was affected by male gender $(\mathrm{OR}=1.22[1.08,1.39], p=0.002)$ (Figure 5A), diabetes $(\mathrm{OR}=0.88[0.79,0.98], p=0.019)$ (Figure 5B); borderline significant for age $(\mathrm{OR}=0.93[0.87,1.00]$, $p=0.061)$ and hypertension $(\mathrm{OR}=0.93[0.87,1.00]$, $p=0.052)$. 
TABLE 1 | Baseline characteristics of the included studies.

\begin{tabular}{|c|c|c|c|c|c|c|c|c|c|}
\hline Authors & Design & Sample size & $\begin{array}{c}\text { Vitamin D } \\
\text { cut-off (ng/mL }\end{array}$ & $\begin{array}{l}\text { Outcome of } \\
\text {-) interest }\end{array}$ & Age (years) & Male (\%) & Diabetes (\%) & $\begin{array}{l}\text { Hypertension } \\
\text { (\%) }\end{array}$ & NOS \\
\hline Abrishami et al. (10) & $\begin{array}{l}\text { Retrospective } \\
\text { observational }\end{array}$ & 73 & $<25$ & Mortality & 55.2 & 64.4 & 15.1 & 24.7 & 8 \\
\hline Baktash et al. (9) & $\begin{array}{l}\text { Retrospective } \\
\text { Observational }\end{array}$ & 105 & $\leq 30$ & $\begin{array}{l}\text { Mortality } \\
\text { IMV }\end{array}$ & 81 & 54.3 & 32.3 & 51.4 & 6 \\
\hline Cereda et al. (22) & $\begin{array}{l}\text { Prospective } \\
\text { Observational }\end{array}$ & 129 & $<20$ & $\begin{array}{l}\text { Mortality } \\
\text { Severity }\end{array}$ & 77 & 54.3 & 30.7 & 70.1 & 8 \\
\hline Hastie et al. (21) & Observational & 656 & $<25$ & Mortality & - & - & - & - & 7 \\
\hline Hernández et al. (20) & $\begin{array}{l}\text { Restrospective } \\
\text { Observational } \\
\text { (case-control) }\end{array}$ & 216 & $<20$ & $\begin{array}{l}\text { Mortality } \\
\text { Severity } \\
\text { Susceptibility }\end{array}$ & 61 & 62.4 & 16.5 & 40 & 6 \\
\hline Im et al. (18) & $\begin{array}{l}\text { Retrospective } \\
\text { Observational }\end{array}$ & 200 & $<20$ & Susceptibility & $\begin{array}{c}57.5 \\
\text { (COVID-19) }\end{array}$ & - & - & - & 5 \\
\hline Jain et al. (12) & $\begin{array}{l}\text { Prospective } \\
\text { Observational }\end{array}$ & 154 & $<20$ & Mortality & 46.1 & 61.7 & - & - & 5 \\
\hline Katz et al. (11) & Cross-Sectional & $\begin{array}{c}987,849 \\
971 \text { (COVID-19) }\end{array}$ & Deficiency & Susceptibility & Stratified & 48.4 & - & - & 6 \\
\hline Luo et al. (14) & Cross-Sectional & 895 & $<30$ & $\begin{array}{l}\text { Mortality } \\
\text { Severity } \\
\text { Susceptibility }\end{array}$ & 55.5 & 45.3 & - & - & 6 \\
\hline Maghbooli et al. (19) & $\begin{array}{l}\text { Retrospective } \\
\text { Observational }\end{array}$ & 235 & $<30$ & Severity & 58.7 & 61.3 & 36.6 & 44.4 & 6 \\
\hline Meltzer et al. (17) & $\begin{array}{l}\text { Retrospective } \\
\text { Observational }\end{array}$ & 489 & $<20$ & Susceptibility & 49.2 & 25 & 28 & 53 & 8 \\
\hline Merzon et al. (16) & $\begin{array}{l}\text { Retrospective } \\
\text { Observational }\end{array}$ & 7,807 & $<20$ & Susceptibility & 44 & 41.4 & - & - & 7 \\
\hline & & 782 (COVID-19) & & & & & & & \\
\hline adujkovic et al. (15) & $\begin{array}{l}\text { Retrospective } \\
\text { Observational }\end{array}$ & 185 & $<20$ & Mortality & 60 & 51 & 10 & - & 8 \\
\hline & & & & Severity & & & & & \\
\hline De Smet et al. (13) & $\begin{array}{l}\text { Retrospective } \\
\text { Observational }\end{array}$ & 186 & $<20$ & Mortality & 69 & 58.6 & 14 & - & 8 \\
\hline
\end{tabular}

IMV, Invasive Mechanical Ventilation; NOS, Newcastle-Ottawa Scale.

\section{DISCUSSION}

This meta-analysis indicates that low serum 25-OHD levels was associated with higher infection, severe COVID-19, and mortality rate.

Pooled analysis showed that the susceptibility to COVID-19 was higher in patients with low serum 25-OHD. Meta-regression analysis showed that age and gender (male) significantly increase the association. Thus, elderly patients with low serum 25OHD are more susceptible to COVID-19 compared to nonelderly patients with low serum 25-OHD. Older adults may experience immunosenescence and inflammaging which may affect immune responses against infection, thus contributing to susceptibility $(23,24)$. Elderly population produces $75 \%$ less cutaneous vitamin D3 than young adults and is thus more prone to lower serum 25-OHD level (25). These, in combination, may explain the increased susceptibility to COVID-19 in older adults. Meta-regression showed that male gender affects the association between low serum 25-OHD and susceptibility to
COVID-19 and mortality. Vitamin D affects androgen synthesis in testicular cells, and endogenous testosterone may account for differences in properties of low 25-OHD in males and females $(26,27)$. This may be of special importance in elderly patients. The exact mechanism on why gender plays a role requires further investigation.

The current analysis showed that low serum 25-OHD was associated with higher mortality and severe COVID-19. However, it should be noted that some of studies were excluded because they only provide a comparison of serum 25-OHD levels in a continuous variable, several of these studies showed a no significant difference between mean serum 25-OHD and mortality and severity of COVID-19. A prospective multicenter observational CovILD study of 109 patients by Pizzini et al. (28) indicates that low serum 25-OHD levels at the onset or 8-week follow-up were not associated with persistent symptom burden, lung function impairment, ongoing inflammation, or more severe CT abnormalities. Our study also indicates that the susceptibility to COVID-19 might be higher in patients with low 


\section{Low Serum 25-hydroxyvitamin D and COVID-19 Infection Rate}

Study

Odds Ratio

Weight

with $95 \% \mathrm{Cl}$

(\%)

Hernandez 2020

Im 2020

Katz 2020

Luo 2020

Meltzer 2020

Merzon 2020

Overall

Heterogeneity: $\tau^{2}=0.28, I^{2}=92.56 \%, H^{2}=13.45$

Test of $\theta_{\mathrm{i}}=\theta_{\mathrm{j}}: \mathrm{Q}(5)=67.23, \mathrm{p}=0.00$

Test of $\theta=0: z=4.28, p=0.00$
$5.24[3.35,8.20] 16.20$

$3.72[1.83,7.57] \quad 13.11$

$4.63[3.71,5.78] \quad 18.36$

$1.88[1.57,2.26] \quad 18.61$

$1.63[0.98,2.71] 15.50$

$1.58[1.24,2.01] \quad 18.21$

$2.71[1.72,4.29]$
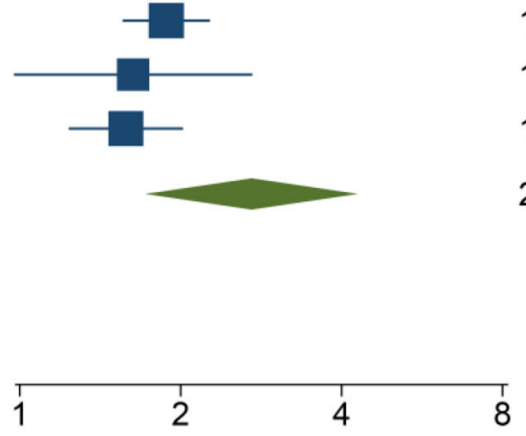

\section{Random-effects DerSimonian-Laird model}

FIGURE 2 | Low Serum 25-hydroxyvitamin D and COVID-19 infection rate.

serum 25-OHD, however, a data of 1,326 patients from the UK biobank cohort indicates that Vitamin D level, adjusted with gender, age, and ethnicity was not significant for susceptibility to COVID-19.

Studies evaluating the serum 25-OHD level often have different cut-off points, we included those with $20-30 \mathrm{ng} / \mathrm{mL}$ cutoff points. There was a study showed that $10 \mathrm{ng} / \mathrm{mL}$ cut-off point was associated with tenfold risk of mortality (29).

Another possible explanation for the association between low serum 25-OHD and poor outcome is that patients with severe illness are often bedridden and have low intake, leading to low serum 25-OHD level (30). Thus subsequent studies need to be able to demonstrate a causal relationship in order to solidify the evidence. Patients with older age and comorbidities such as obesity, diabetes, cardiovascular disease, hypertension, heart failure are also associated with higher mortality in patients with COVID-19 (31-38). Obesity itself was shown to be associated with low serum 25-OHD level (32). The heterogeneity of the pooled effect estimate was high, metaregression analysis indicates that gender and comorbidities affect the association between low serum 25-OHD and mortality; thus, one of the potential causes of heterogeneity is the variation in the proportion of comorbidities. Thus a welldesigned prospective large cohort studies with rigorous statistical analysis and adequate adjustment to covariates are required to obtain the "true" effect of low serum 25-OHD on mortality in COVID-19.

Previously, a meta-analysis showed that Vitamin D supplementation was associated with reduced risk for acute respiratory tract infection (6). Subgroup analysis in the study indicate that vitamin D3 benefit was observed in $<800$ international units (IU), a statistically non-significant trend in 800-2,000 IU, and no benefit in $\geq 2,000$ IU supplementation. The potential risk of bias should be noted, the observation was made based on five, nine, and eleven studies respectively; with the statistical significance noted in pooling of five studies. Rastogi et al. (39) conducted a randomized controlled study with short term administration of high-dose vitamin $\mathrm{D}$ in asymptomatic or mildly symptomatic COVID-19 patients with vitamin D deficiency and noted that a greater proportion of patients turned negative in the vitamin D supplementation group. Additionally, there was a significant decrease in fibrinogen in patients receiving vitamin $\mathrm{D}$. Nonetheless, the study has a small sample size and lacks adjustment for potential confounders on their analysis. These analyses also did not hard endpoints such as mortality or requirement for a more intensive care. Cohort studies have shown potential benefit of vitamin $\mathrm{D}$ supplementation in terms of COVID-19 severity (40). A quasiexperimental study indicate possible benefit of vitamin D bolus on survival of COVID-19 patients in a nursing home (41), however, the control arm has only nine patients compared to 57 in the interventional arm. It is unclear why the control group did not receive vitamin $\mathrm{D}$ bolus, this might be a potentially important confounder.

\section{Clinical Implications}

Low serum 25-OHD levels was shown to be associated with higher infection rate, severity, and mortality. Whether the relationship is causal remains to be investigated. Vitamin D supplementation is economical and potentially beneficial. Thus, 
A

Low Serum 25-hydroxyvitamin D and Severe COVID-19

Odds Ratio Weight

Study with $95 \% \mathrm{Cl}$

Baktas 2020 (IMV)

Cereda 2020

Hernandez 2020

Luo 2020

Radujkovic 2020

Overall

Heterogeneity: $\tau^{2}=0.30, \mathrm{I}^{2}=64.25 \%, \mathrm{H}^{2}=2.80$

Test of $\theta_{l}=\theta_{j}: Q(4)=11.19, p=0.02$

Test of $\theta=0: z=2.46, p=0.01$

$4.15[1.05,16.37] 12.83$

$1.11[0.75,1.65] 29.66$

$1.55[0.66,3.65] 20.66$

$2.72[1.23,6.01] 21.84$

$5.75[1.73,19.10] 15.01$

$2.19[1.17,4.10]$

Random-effects DerSimonian-Laird model

B

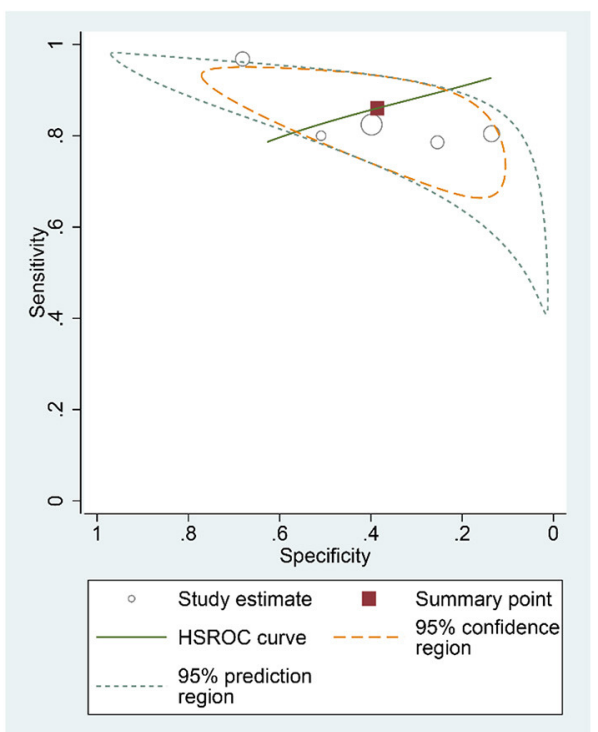

C

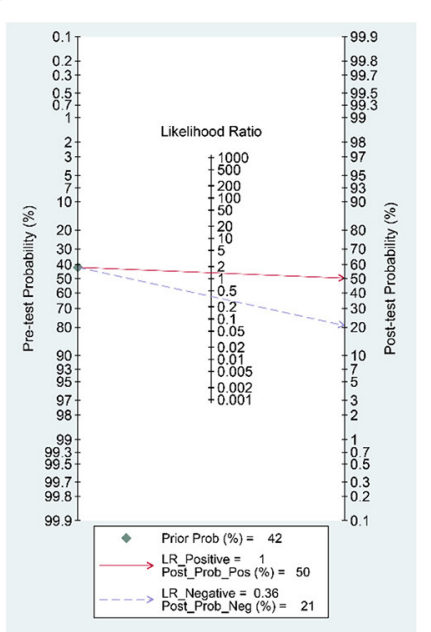

FIGURE 3 | Low Serum 25-hydroxyvitamin D and Severe COVID-19. Forest-plot (A), HSROC curve (B), and Fagan's Nomogram (C). HSROC, hierarchical summary receiver operating characteristic. 
A

\section{Low Serum 25-hydroxyvitamin D and Mortality}

Study

Odds Ratio

Weight

Abrishami 2020

with $95 \% \mathrm{Cl}$

(\%)

Baktas 2020

Cereda 2020

Smet 2020

Hastie 2020

Hernandez 2020

Jain 2020

Luo 2020

Overall

Heterogeneity: $\tau^{2}=1.01, \mathrm{I}^{2}=80.27 \%, \mathrm{H}^{2}=5.07$

$7.77[1.87,32.23] 11.45$

$1.40[0.36,5.46] 11.79$

$0.64[0.26,1.56] 14.45$

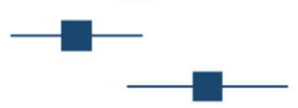

$3.87[1.30,11.54] 13.32$

$1.61[1.14,2.27] 16.89$

$22.19[7.47,65.91] \quad 13.34$

Test of $\theta_{\mathrm{i}}=\theta_{\mathrm{j}}: \mathrm{Q}(7)=35.47, \mathrm{p}=0.00$

Test of $\theta=0: z=2.68, p=0.01$

$8.30[1.86,37.04] 11.05$

$1.07[0.12,9.79] \quad 7.71$

$3.08[1.35,7.00]$

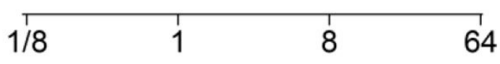

Random-effects DerSimonian-Laird model

B

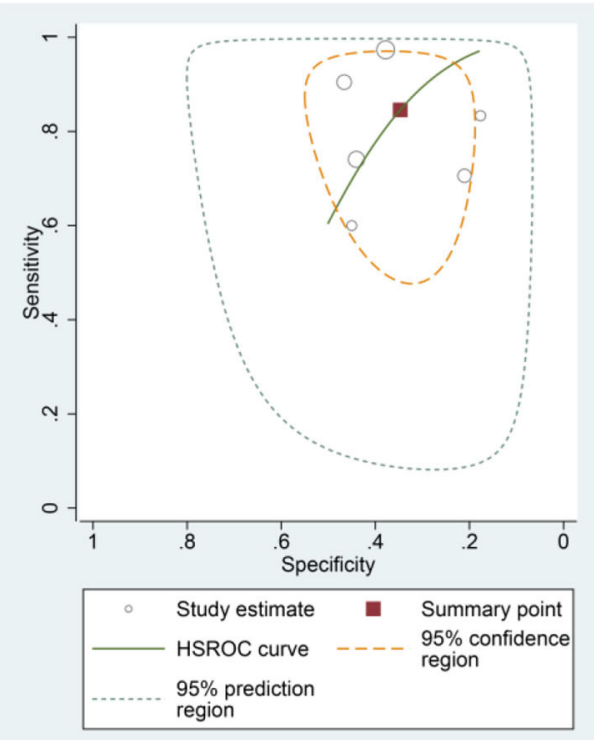

C

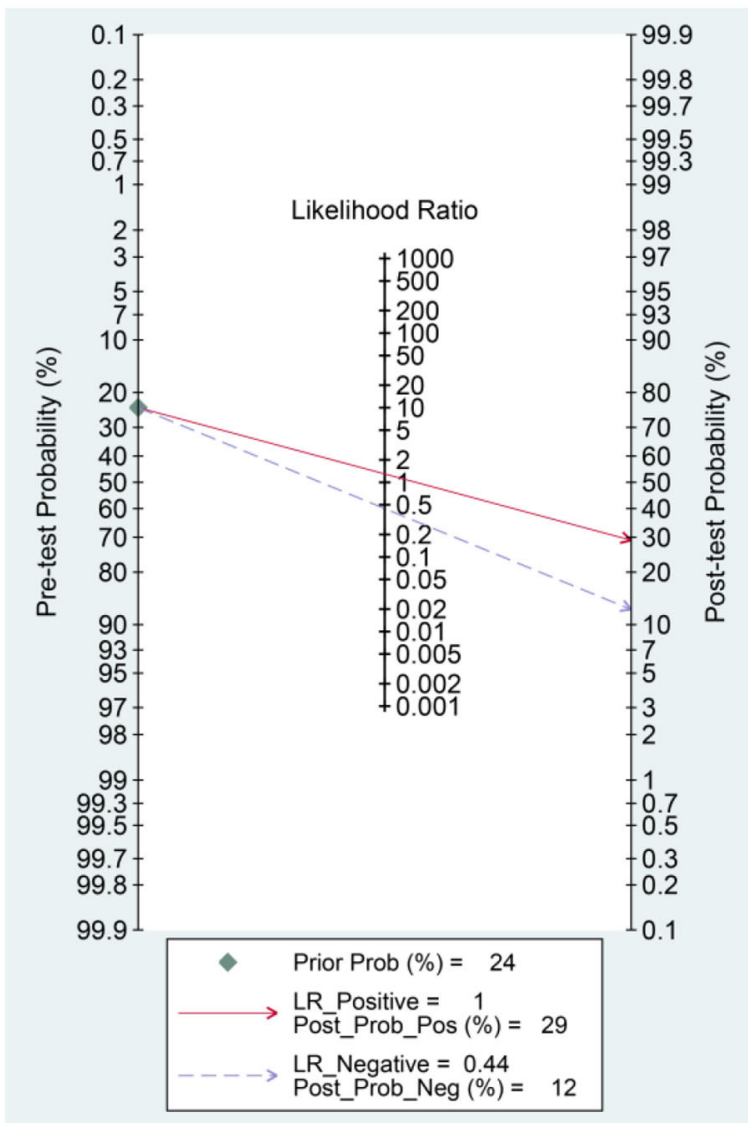

FIGURE 4 | Low Serum 25-hydroxyvitamin D and Mortality. Forest-plot (A), HSROC curve (B), and Fagan's Nomogram (C). HSROC, hierarchical summary receiver operating characteristic. 
A

\section{Bubble plot}

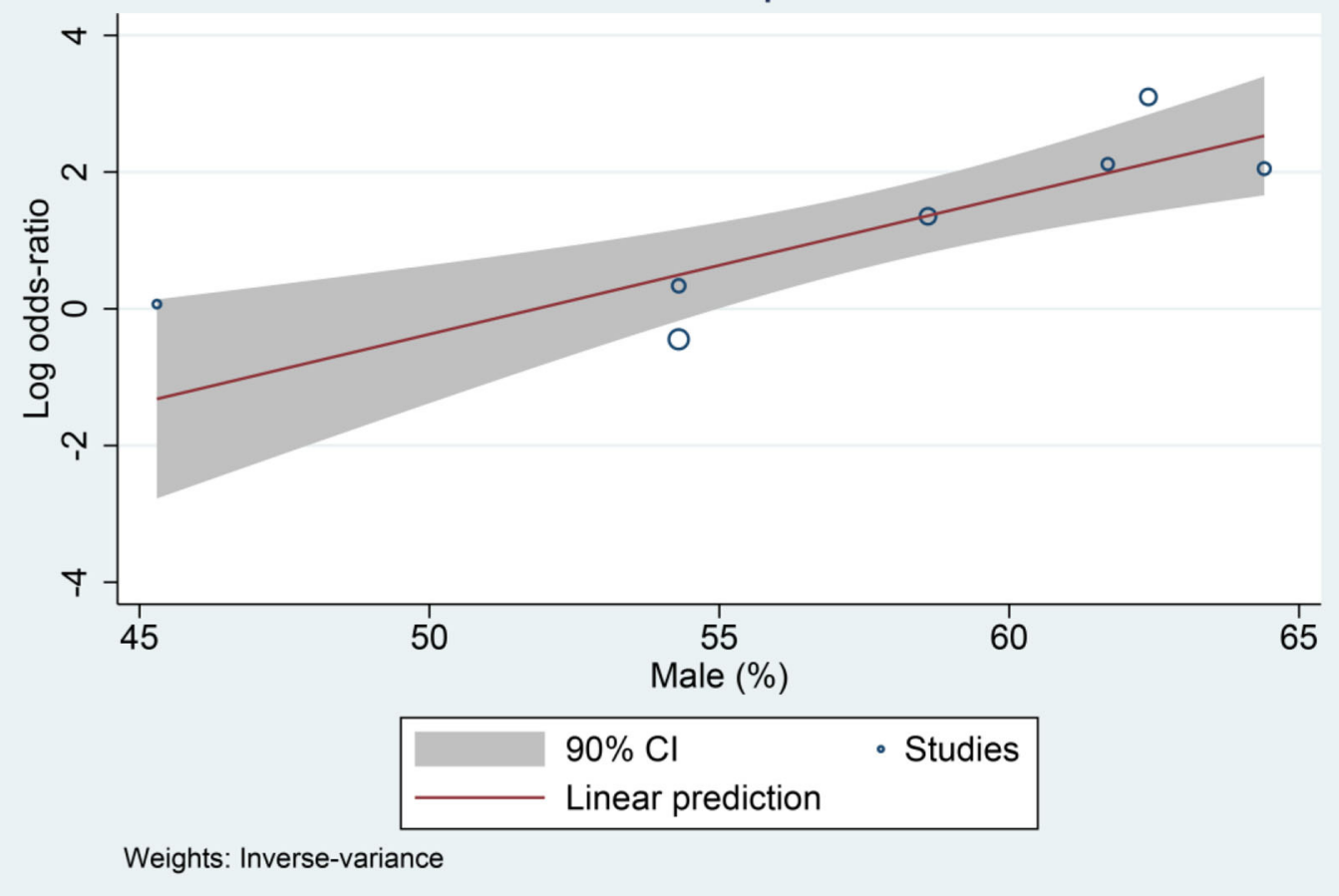

B

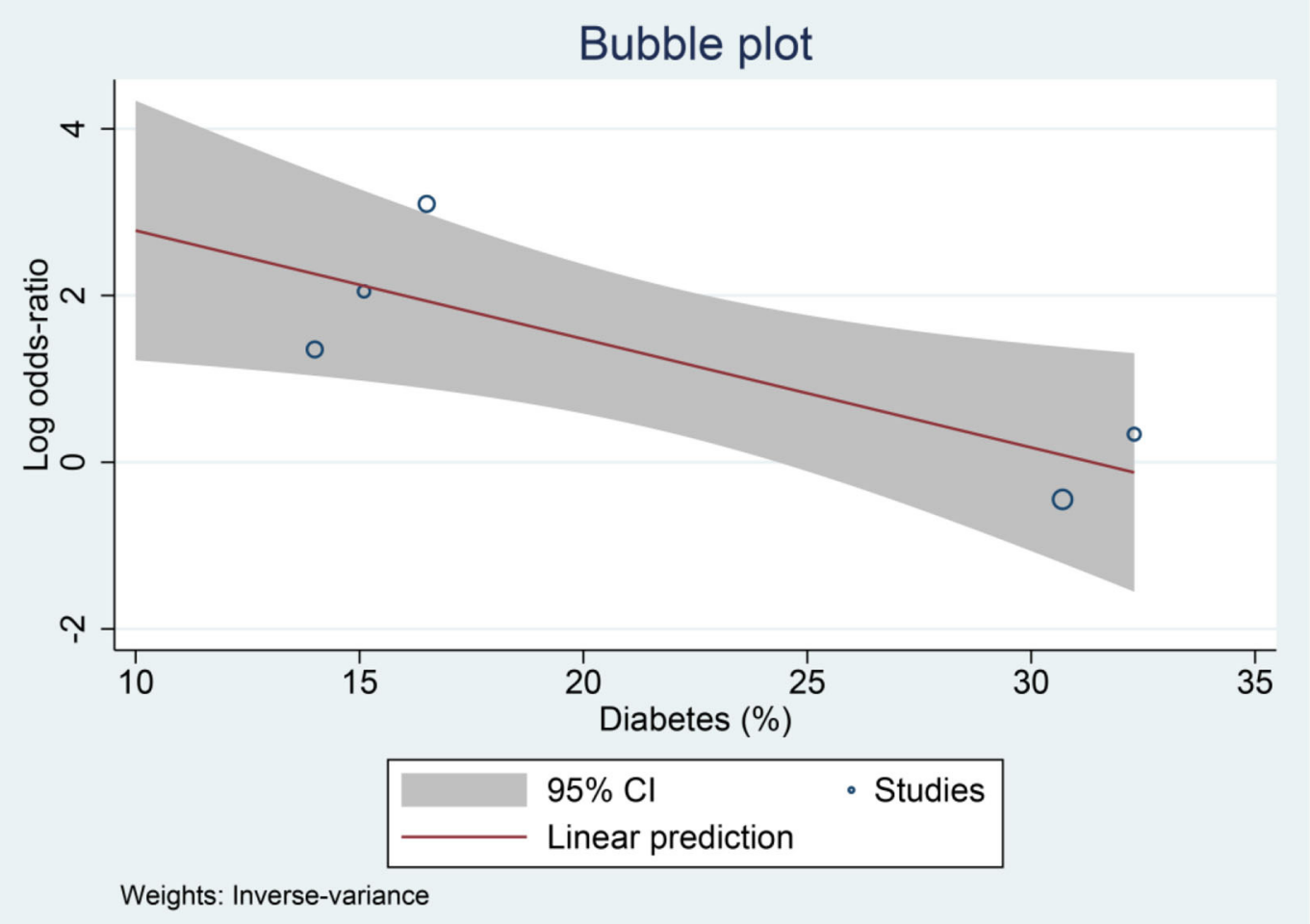

FIGURE 5 | Meta-regression Analysis. Male (A) and diabetes (B) 
it is recommended to provide supplementation to the Vitamin D deficient patients. Nevertheless, high quality randomized controlled trials are required to determine whether routine Vitamin D supplementation will be useful.

\section{Limitation}

The risk of publication bias, which is caused by positive studies are more likely to be published compared to the negative studies, cannot be ruled out. The retrospective design of the studies presents as a potential source of bias. The cutoff point slightly varies among the pooled analysis. Potential unaccounted confounders may cause bias in the studies, for example, bedridden patients often have low serum 25-OHD compared to the healthy counterpart.

One of the study by Katz et al. (11) has the largest sample size of 987,849 . However, we only take Katz et al. study for susceptibility, thus it did not affect the pooled mortality and severity. For the susceptibility analysis, Katz et al. contributes to $18.36 \%$ of the weight for susceptibility. Largest contributor is Luo et al. which contributes to $18.61 \%$ and the smallest was $\mathrm{Im}$ et al. to $13.11 \%$. Thus despite the large sample size compared to the others, it was not expected to change the direction of effect estimate. However, smallstudy effects in the pooled effect estimate for susceptibility

\section{REFERENCES}

1. Fahmi I. \#Covid19 Coronavirus Disease 2019 Situation Report - 31. (2020). Available online at: https://pers.droneemprit.id/covid19/

2. Lim MA, Pranata R, Huang I, Yonas E, Soeroto AY, Supriyadi R. Multiorgan failure with emphasis on acute kidney injury and severity of COVID-19: systematic review and meta-Analysis. Can J Kidney Heal Dis. (2020) 7:205435812093857. doi: 10.1177/20543581209 38573

3. Santoso A, Pranata R, Wibowo A, Al-Farabi MJ, Huang I, Antariksa B. Cardiac injury is associated with mortality and critically ill pneumonia in COVID19: a meta-analysis. Am J Emerg Med. (2020). doi: 10.1016/j.ajem.2020.04.052. [Epub ahead of print].

4. Almerighi C, Sinistro A, Cavazza A, Ciaprini C, Rocchi G, Bergamini A. 1 $\alpha, 25$-Dihydroxyvitamin D3 inhibits CD40L-induced pro-inflammatory and immunomodulatory activity in Human Monocytes. Cytokine. (2009) 45:1907. doi: 10.1016/j.cyto.2008.12.009

5. Park S, Lee MG, Hong SB, Lim CM, Koh Y, Huh JW. Effect of vitamin D deficiency in korean patients with acute respiratory distress syndrome. Korean J Intern Med. (2018) 33:1129-36. doi: 10.3904/kjim.2017.380

6. Martineau AR, Jolliffe DA, Hooper RL, Greenberg L, Aloia JF, Bergman P, et al. Vitamin D supplementation to prevent acute respiratory tract infections: systematic review and meta-analysis of individual participant data. BMJ. (2017) 356:i6583. doi: 10.1136/bmj.i6583

7. Henrina J, Lim MA, Pranata R. COVID-19 and misinformation: how an infodemic fueled the prominence of vitamin D. Br J Nutr. (2020) 125:35960. doi: 10.1017/S0007114520002950

8. Metlay JP, Waterer GW, Long AC, Anzueto A, Brozek J, Crothers $\mathrm{K}$, et al. Diagnosis and treatment of adults with communityacquired pneumonia. Am J Respir Crit Care Med. (2019) 200:E45-E67. doi: 10.1164/rccm.201908-1581ST

9. Baktash V, Hosack T, Patel N, Shah S, Kandiah P, Van Den Abbeele K, et al. Vitamin D status and outcomes for hospitalised older patients with COVID19. Postgrad Med J. (2020) 2:1-6. doi: 10.1136/postgradmedj-2020-138712

10. Abrishami A, Dalili N, Mohammadi Torbati P, Asgari R, Arab-Ahmadi M, Behnam B, et al. Possible association of vitamin D status with lung might be caused by the studies with minimal sample because they are weighted almost equally with the larger studies (42). Finally, meta-regression analysis was also based on small number of studies.

In conclusion, low serum 25-OHD level was associated with higher rate of COVID-19 infection, severe presentation, and mortality.

\section{DATA AVAILABILITY STATEMENT}

The original contributions generated for the study are included in the article/supplementary material, further inquiries can be directed to the corresponding author/s.

\section{AUTHOR CONTRIBUTIONS}

MA: conceptualization, investigation, writing - original draft, writing - review and editing, and supervision. AW: data curation, investigation, and writing - original draft. RP: conceptualization, methodology, software, data curation, formal analysis, statistical analysis, investigation, validation, and writing - original draft. BS: investigation, and writing - review and editing. All authors contributed to the article and approved the submitted version. involvement and outcome in patients with COVID-19: a retrospective study. Eur J Nutr. (2020). doi: 10.1007/s00394-020-02411-0. [Epub ahead of print].

11. Katz J, Yue S, Xue W. Increased risk for COVID-19 in patients with vitamin D deficiency. Nutrition. (2021) 84:111106. doi: 10.1016/j.nut.2020.111106

12. Jain A, Chaurasia R, Sengar NS, Singh M, Mahor S, Narain S. Analysis of vitamin $\mathrm{D}$ level among asymptomatic and critically ill COVID-19 patients and its correlation with inflammatory markers. Sci Rep. (2020) 10:18. doi: 10.1038/s41598-020-77093-z

13. De Smet D, De Smet K, Herroelen P, Gryspeerdt S, Martens GA. Serum 25(OH)D level on hospital admission associated with COVID-19 stage and mortality. Am J Clin Pathol. (2020) 25:1-8. doi: 10.1093/ajcp/aqaa252

14. Luo X, Liao Q, Shen Y, Li H, Cheng L. Vitamin D deficiency is inversely associated with COVID-19 incidence and disease severity in Chinese people. J Nutr. (2021) 151:98-103. doi: 10.1093/jn/nxaa332

15. Radujkovic A, Hippchen T, Tiwari-Heckler S, Dreher S, Boxberger M, Merle U. Vitamin D deficiency and outcome of COVID-19 patients. Nutrients. (2020) 12:1-13. doi: 10.3390/nu12092757

16. Merzon E, Tworowski D, Gorohovski A, Vinker S, Golan Cohen A, Green I, et al. Low plasma $25(\mathrm{OH})$ vitamin $\mathrm{D}$ level is associated with increased risk of COVID-19 infection: an Israeli population-based study. FEBS J. (2020) 287:3693-702. doi: 10.1111/febs.15495

17. Meltzer DO, Best TJ, Zhang H, Vokes T, Arora V, Solway J. Association of vitamin D status and other clinical characteristics with COVID-19 test results. JAMA Netw open. (2020) 3:e2019722. doi: 10.1001/jamanetworkopen.2020.19722

18. Im JH, Je YS, Baek J, Chung MH, Kwon HY, Lee JS. Nutritional status of patients with COVID-19. Int J Infect Dis. (2020) 100:3903. doi: 10.1016/j.ijid.2020.08.018

19. Maghbooli Z, Sahraian MA, Ebrahimi M, Pazoki M, Kafan S, Tabriz HM, et al. Vitamin D sufficiency, a serum 25-hydroxyvitamin D at least $30 \mathrm{ng} / \mathrm{mL}$ reduced risk for adverse clinical outcomes in patients with COVID-19 infection. PLoS One. (2020) 15:1-13. doi: 10.1371/journal.pone.0239799

20. Hernández JL, Nan D, Fernandez-Ayala M, García-Unzueta M, HernándezHernández MA, López-Hoyos M, et al. Vitamin D status in hospitalized patients with SARS-CoV-2 infection. J Clin Endocrinol Metab. (2020) 106:1343-53. doi: 10.1210/clinem/dgaa733 
21. Hastie CE, Pell JP, Sattar N. Vitamin D and COVID-19 infection and mortality in UK Biobank. Eur J Nutr. (2020) 60:545-48. doi: 10.1101/2020.06.26.20140921

22. Cereda E, Bogliolo L, Klersy C, Lobascio F, Masi S, Crotti S, et al. Vitamin D $25 \mathrm{OH}$ deficiency in COVID-19 patients admitted to a tertiary referral hospital. Clin Nutr. (2020). doi: 10.1016/j.clnu.2020.10.055. [Epub ahead of print].

23. Shea PM, Griffin T s. P, Brennan M, Mulkerrin EC. COVID-19: the older adult and the importance of vitamin D sufficiency. J Nutr Sci. (2020) 9:e40. doi: $10.1017 /$ jns.2020.36

24. Huang I, Pranata R. Lymphopenia in severe coronavirus disease-2019 (COVID-19): systematic review and meta-analysis. J Intensive Care. (2020) 8:36. doi: 10.1186/s40560-020-00453-4

25. Kennel KA, Drake MT, Hurley DL. Vitamin D deficiency in adults: when to test and how to treat. Mayo Clin Proc. (2010) 85:7528. doi: $10.4065 / \mathrm{mcp} .2010 .0138$

26. Hofer D, Münzker J, Schwetz V, Ulbing M, Hutz K, Stiegler P, et al. Testicular synthesis and vitamin D action. J Clin Endocrinol Metab. (2014) 99:376673. doi: 10.1210/jc.2014-1690

27. Sanghera DK, Sapkota BR, Aston CE, Blackett PR. Vitamin D status, gender differences, and cardiometabolic health disparities. Ann Nutr Metab. (2017) 70:79-87. doi: 10.1159/000458765

28. Pizzini A, Aichner M, Sahanic S, Böhm A, Egger A, Hoermann G, et al. Impact of vitamin d deficiency on covid-19-a prospective analysis from the covild registry. Nutrients. (2020) 12:1-9. doi: 10.3390/nu12092775

29. Carpagnano GE, Di Lecce V, Quaranta VN, Zito A, Buonamico E, Capozza E, et al. Vitamin D deficiency as a predictor of poor prognosis in patients with acute respiratory failure due to COVID-19. J Endocrinol Invest. (2020) 44:765-71. doi: 10.1007/s40618-020-01370-x

30. Egsmose C, Lund B, Mcnair P, Lund B, Storm T, Sørensen OH. Low serum levels of 25-hydroxyvitamin $\mathrm{D}$ and 1,25-dihydroxyvitamin $\mathrm{D}$ in institutionalized old people: influence of solar exposure and vitamin D supplementation. Age Ageing. (1987) 16:35-40. doi: 10.1093/ageing/16.1.35

31. Pranata R, Huang I, Lim MA, Wahjoepramono EJ, July J. Impact of cerebrovascular and cardiovascular diseases on mortality and severity of COVID-19-systematic review, metaanalysis, and meta-regression. J Stroke Cerebrovasc Dis. (2020) 29:104949. doi: 10.1016/j.jstrokecerebrovasdis.2020.104949

32. Pranata R, Lim MA, Yonas E, Vania R, Lukito AA, Siswanto BB, et al. Body mass index and outcome in patients with COVID-19: a dose-response metaanalysis. Diabetes Metab. (2020) 47:101178. doi: 10.1016/j.diabet.2020.07.005

33. Pranata R, Supriyadi R, Huang I, Permana H, Lim MA, Yonas E, et al. The association between chronic kidney disease and new onset renal replacement therapy on the outcome of COVID-19 patients: a meta-analysis. Clin Med Insights Circ Respir Pulm Med. (2020) 14:1179548420959165. doi: 10.1177/1179548420959165

34. Pranata R, Lim MA, Huang I, Raharjo SB, Lukito AA. Hypertension is associated with increased mortality and severity of disease in COVID-19 pneumonia: A systematic review, meta-analysis and meta-regression. J Renin Angiotensin Aldosterone Syst. (2020) 21:147032032092689. doi: 10.1177/1470320320926899

35. Huang I, Lim MA, Pranata R. Diabetes mellitus is associated with increased mortality and severity of disease in COVID-19 pneumonia - a systematic review, meta-analysis, and meta-regression: diabetes and COVID-19. Diabetes Metab Syndr Clin Res Rev. (2020) 14:395-403. doi: 10.1016/j.dsx.2020.04.018

36. Yonas E, Alwi I, Pranata R, Huang I, Lim MA, Gutierrez EJ, et al. Effect of heart failure on the outcome of COVID-19 - a meta analysis and systematic review. Am J Emerg Med. (2020). doi: 10.1016/j.ajem.2020.07.009. [Epub ahead of print].

37. Pranata R, Henrina J, Lim MA, Lawrensia S, Yonas E, Vania R, et al. Clinical frailty scale and mortality in COVID-19: a systematic review and doseresponse meta-analysis: Clinical Frailty Scale in COVID-19. Arch Gerontol Geriatr. (2021) 93:104324. doi: 10.1016/j.archger.2020.104324

38. July J, Pranata R. Prevalence of dementia and its impact on mortality in patients with coronavirus disease 2019: a systematic review and meta-analysis. Geriatr Gerontol Int. (2020) 21:172-77. doi: 10.1111/ggi. 14107

39. Rastogi A, Bhansali A, Khare N, Suri V, Yaddanapudi N, Sachdeva N, et al. Short term, high-dose vitamin D supplementation for COVID19 disease: a randomised, placebo-controlled, study (SHADE study). Postgrad Med J. (2020). doi: 10.1136/postgradmedj-2020-139065. [Epub ahead of print].

40. Tan CW, Ho LP, Kalimuddin S, Cherng BPZ, Teh YE, Thien SY, et al. Cohort study to evaluate effect of vitamin D, magnesium, and vitamin $\mathrm{B} 12$ in combination on severe outcome progression in older patients with coronavirus (COVID-19). Nutrition. (2020) 79-80:111017. doi: 10.1016/j.nut.2020.111017

41. Annweiler C, Hanotte B, Grandin de l'Eprevier C, Sabatier JM, Lafaie L, Célarier T. Vitamin D and survival in COVID19 patients: a quasi-experimental study. $J$ Steroid Biochem Mol Biol. (2020) 204:105771. doi: 10.1016/j.jsbmb.2020.1 05771

42. Zhang Z, Xu X, Ni H. Small studies may overestimate the effect sizes in critical care meta-analyses: a meta-epidemiological study. Crit Care. (2013) 17:R2. doi: $10.1186 / \mathrm{cc} 11919$

Conflict of Interest: The authors declare that the research was conducted in the absence of any commercial or financial relationships that could be construed as a potential conflict of interest.

Copyright (c) 2021 Akbar, Wibowo, Pranata and Setiabudiawan. This is an openaccess article distributed under the terms of the Creative Commons Attribution License (CC BY). The use, distribution or reproduction in other forums is permitted, provided the original author(s) and the copyright owner(s) are credited and that the original publication in this journal is cited, in accordance with accepted academic practice. No use, distribution or reproduction is permitted which does not comply with these terms. 